\title{
Functionalized nanodiamond as potential synergist in flame-retardant ethylene vinyl acetate ${ }^{\not r}$
}

\author{
Charlène Presti ${ }^{\mathrm{a}, \mathrm{b}}$, Laurent Ferry ${ }^{\mathrm{b}, *}$, Johan G. Alauzun ${ }^{\mathrm{a}, *}$, Loïc Dumazert ${ }^{\mathrm{b}}$, Benjamin Gallard ${ }^{\mathrm{b}}$, \\ Jean-Christophe Quantin ${ }^{\mathrm{b}}$, José-Marie Lopez Cuesta ${ }^{\mathrm{b}}$, P. Hubert Mutin ${ }^{\mathrm{a}}$ \\ a Institut Charles Gerhardt Montpellier, UMR 5253, CNRS-UM-ENSCM, Université de Montpellier, Place Eugene Bataillon, CC1701, F-34095 Montpellier Cedex 5, France \\ b Centre des Matériaux des Mines d'Alès (C2MA), 6, Avenue de Clavières, 30319 Alès Cedex, France
}

\section{A B S T R A C T}

Pristine and phosphorylated detonation nanodiamonds (ND) were incorporated in ethylene vinyl acetate (EVA) as potential synergist agents to improve flame retardancy. Combinations of $5 \mathrm{wt} \%$ of pristine or modified ND and 20 or 25 wt $\%$ of Ammonium Polyphosphate (APP) were investigated using ThermoGravimetric Analysis (TGA), Pyrolysis Combustion Flow Calorimeter (PCFC), and Cone Calorimeter (CC). The study of thermal stability shows that APP and pure ND interacts, resulting in the formation of a char residue which is stable up to $7500^{\circ} \mathrm{C}$. A strong reduction in the peak of HRR at Cone Calorimeter is highlighted for APP/ND combinations. PCFC data show that the peak of heat release rate (pHRR) decreases with the additive content. All these experiments suggest the formation of a thick charring layer, able to protect the material during thermal degradation. SEM micrographs confirm that EVA/APP/ND residues are more cohesive than EVA/APP ones.

\section{Introduction}

Ethylene Vinyl Acetate (EVA) is frequently used in the cable industry as flexible sheath. Due to its chemical composition, this polymer is easily flammable and decomposes in two steps: elimination of the side group with acetic acid release and then breaking of the main chain. These chemical processes can be highlighted through thermal analysis. In the past, halogen compounds were used to improve flame retardancy of EVA copolymers, but due to corrosiveness and environmental concerns, industry has been pushed to select new approaches. The most commonly used halogen free fire retardant formulations for this kind of application are based on hydrated minerals, such as aluminum trihydroxide (ATH) or magnesium dihydroxide (MDH) [1-4]. Such hydroxides act as fire retardants mainly through endothermic dehydration processes and dilution of gas phase surrounding the material, but very high filler contents are needed to obtain satisfactory fire properties. Even so, various studies have highlighted the interest of combining hydrated mineral with synergistic agents such as organomodified layered silicates or silicas [5-7]. Another approach to improve fire performance of EVA is that of intumescence which aims to create an expanded and charred layer at the surface of polymer [8]. This layer acts as a shield able to limit mass and heat transfer through the material during its thermal degradation. Thus, the heat flux arising from the flame to the polymer matrix which is responsible for the fuel production and thereby the spread of fire can be reduced. On the whole, intumescent formulations consist of three components: an acid source (polyphosphates, borates...), a charring agent (polyols, polyurethanes, polyamides...) and a blowing agent (melamine or its salts). The exposure to a heat source of polymers containing such additives leads to the transformation of the acid source into an inorganic acid which can dehydrate the carbonizing compound, what results in the formation of a cellular structure, promoted by the blowing agent or by the release of gaseous decomposition products. In various research works, polyamide 6 (PA6) and ammonium polyphosphate (APP) have been combined as flame retardant system for EVA $[9,10]$. More recently, other original intumescent systems have been assessed in EVA such as for example cyclodextrin nanosponge/APP compound [11] or chitosan/ phytic acid polyelectrolyte complex [12]. Moreover, to improve the efficiency of intumescent system, synergistic agents such as nanoparticles and more particularly organomodified layered silicates [13,14], but also expanded and natural graphite [15] have been investigated. It can be surprising to use pure carbon to improve fire retardancy of polymers, but it can be shown that graphite compounds and even graphene oxide compounds can act as char promoters [16-18]. In addition, other studies have shown that carbon structures such as carbon nanotubes $[19,20]$ or graphene $[21,22]$ could create a thermal

\footnotetext{
$\stackrel{7}{*}$ The authors declare no competing financial interest.

* Corresponding authors.

E-mail addresses: laurent.ferry@mines-ales.fr (L. Ferry), johan.alauzun@umontpellier.fr (J.G. Alauzun).
} 
barrier limiting the heat flux through the residual material and promoting heat re-radiation.

In recent years nanodiamonds have roused interest in various research areas due to a set of properties such as hardness, chemical inertness, thermal conductivity, electrical insulation, that make them candidates for numerous applications [23-26]. In recent papers, we have shown that surface modification of nanodiamond can be achieved by phosphorylation [27-29]. This reaction was highlighted to enhance the thermal stability of nanoparticles under oxidizing conditions. Oxidation temperature was shifted up to $190^{\circ} \mathrm{C}$ and oxidation rate was greatly decreased. Based on these encouraging results, it was intended to investigate the ability of nanodiamond to improve the fire behavior of a polymeric matrix.

In the present work, pure and surface modified nanodiamonds were used in combination with APP with the objective to improve the reaction-to-fire of EVA. In a first part, the behavior of these composites was studied in order to evidence the potential action of ND on thermal stability and char promotion. In a second part, the fire behavior of the ND containing composites was investigated using calorimetry. An attempt was made to relate the flame retardant action of the system to the microstructure and properties of the composites.

\section{Experimental section}

\subsection{Materials}

Purified detonation nanodiamonds (ND, 99\% purity, $0.2 \mathrm{wt} \%$ of non-diamond carbon) with an average primary particle size of 4 to $5 \mathrm{~nm}$ and a specific surface area of $270 \mathrm{~m}^{2} \mathrm{~g}^{-1}$ were purchased from International Technology Center (ITC, Raleigh, NC, U.S.A.). They were dried before use for $18 \mathrm{~h}$ at $120^{\circ} \mathrm{C}$ under reduced pressure (5.10 $0^{-2}$ mbar).

Ethylene-vinyl-acetate copolymer (EVA) Alcudia PA-440 grade was provided by Repsol (Madrid, Spain) with $28 \mathrm{wt} \%$ of vinyl acetate. Ammonium polyphosphate (APP) was supplied by Clariant (Muttenz, Switzerland) under the grade Exolit AP 423, with an average particle size (D50) of $8 \mu \mathrm{m}$ and approx. $31.5 \mathrm{wt} \%$ in Phosphorus.

\subsection{Material processing}

\subsubsection{Functionalization of the NDs}

Commercial NDs were phosphorylated using $2.5 \mathrm{mmol}$ of phosphoryl chloride $\left(\mathrm{POCl}_{3}\right)$ and $7 \mathrm{mmol}$ of water per gram of $\mathrm{ND}$, according to a previous work [27]. The P content determined by elemental analysis was $5.15 \mathrm{wt} \%$.

\subsubsection{Preparation of EVA composites}

Compositions were compounded using an internal mixer (Thermo Haake, chamber $=60 \mathrm{~cm}^{3}$, speed $=60 \mathrm{rpm}, T=165^{\circ} \mathrm{C}, 3 \mathrm{~min}$ ). The obtained composites were then processed by compression moulding at $165^{\circ} \mathrm{C}$ into disk-shaped (20 bars, diameter $=25 \mathrm{~mm}$, thickness $=1.5 \mathrm{~mm})$ or square-shaped $(100 \mathrm{bars}, 100 \times 100 \times 3 \mathrm{~mm})$ pieces.

The various compositions and designations are given in Table 1.

Table 1

Composition and phosphorus amount of the different compositions.

\begin{tabular}{|c|c|c|c|c|}
\hline Samples & EVA (wt\%) & APP (wt \%) & ND (wt\%) & P (\%) \\
\hline $\mathrm{EVA} / \mathrm{APP}_{20}$ & 80 & 20 & & 6.3 \\
\hline $\mathrm{EVA} / \mathrm{APP}_{25}$ & 75 & 25 & & 7.9 \\
\hline $\mathrm{EVA} / \mathrm{APP}_{20} / \mathrm{ND}_{5}{ }^{\mathrm{b}}$ & 75 & 20 & 5 & 6.3 \\
\hline EVA $/$ APP $_{20} /$ ND- $_{5}{ }^{b}$ & 75 & 20 & 5 & 6.6 \\
\hline
\end{tabular}

a P: phosphorus weight content.

b ND: pristine nanodiamonds; ND-P: phosphorylated nanodiamonds.

\subsection{Sample characterization}

Thermogravimetric analysis (TGA) was performed on $55 \mathrm{mg} \pm \mathbf{5}$ mg samples under air $\left(50 \mathrm{~cm}^{3} \cdot \mathrm{min}^{-1}\right.$ flow $)$ or argon $\left(30 \mathrm{~cm}^{3} \cdot \mathrm{min}^{-1}\right.$ flow) in the $293 \mathrm{~K}$ to $1073 \mathrm{~K}$ temperature range (heating rate of $5 \mathrm{~K} \cdot \mathrm{min}^{-1}$ ) using a Netzsch STA 409 PC Luxx thermobalance. Nevertheless for the sake of brevity only the results under air atmosphere are presented.

Pyrolysis combustion flow calorimeter (PCFC) analysis was carried out according to ASTM D7309 using a FTT apparatus with a heating rate of $1{ }^{\circ} \mathrm{C} \cdot \mathrm{s}^{-1}$, the maximum pyrolysis temperature was $750{ }^{\circ} \mathrm{C}$ and the combustion temperature was $900{ }^{\circ} \mathrm{C}$ (corresponding to complete combustion). The flow in combustor was a mixture of $\mathrm{O}_{2} / \mathrm{N}_{2} 20 / 80$ at $100 \mathrm{~cm}^{3} \cdot \mathrm{min}^{-1}$, the sample weight was $2.5 \mathrm{mg} \pm 0.5 \mathrm{mg}$ and analyses were made in duplicate. Heat Release Rate (HRR) and peak of Heat Release Rate (pHRR) values are measured as a function of temperature and the calculations are based on the Principle of Huggett. Heat Release Capacity (HRC) is defined as the ratio of pHRR with heating rate, therefore pHRR and HRC are equal when the heating rate is $1^{\circ} \mathrm{C} \cdot \mathrm{s}^{-1}$. In our case, the decomposition of samples involved several steps and so sumHRC was used rather than HRC, where sumHRC is the sum of HRC values of every decomposition peak after deconvolution.

Cone calorimetry was carried out using a Fire Testing Technology (FTT) apparatus. Irradiance was fixed at $50 \mathrm{~kW} \cdot \mathrm{m}^{-2}$ and all samples were tested in duplicate. The sample $\left(100 \times 100 \times 3 \mathrm{~mm}^{3}\right)$ is placed on the microbalance support that enables following the evolution of the mass loss during the experiment. From the measurement of the gas flow and of the oxygen concentration, the quantity of heat released per unit of time and surface is calculated: HRR expressed in $\mathrm{kW} \cdot \mathrm{m}^{-2}$. This parameter and the value of its maximum pHRR are usually taken into account for the evaluation of the fire behavior of materials. Data reported are the average of two runs. pHRR data are reproducible within $\pm 5 \%$.

Scanning transmission electron microscopy (STEM) microstructure observations on cryo-microtomed samples of composites were carried out using a FEI Quanta 200 environmental scanning electron microscope under high vacuum at an acceleration voltage of $10 \mathrm{kV}$ or $15 \mathrm{kV}$ (specified on images). Fourty-micrometer-thick films were deposited on copper grids covered with carbon film. EDX mapping was carried out for carbon, phosphorus and oxygen elements.

Rheological properties of materials were performed on an ARES rheometer (TA Instrument) using a parallel plate geometry $(25 \mathrm{~mm}$ diameter) in the oscillatory rotational mode. $2 \mathrm{~min}$ after the sample was loaded, the gap is reduced from 3 to $1 \mathrm{~mm}$ and the excess of material is removed. The test starts $2 \mathrm{~min}$ later. Complex shear viscosities as well as complex shear modulus were determined at $150^{\circ} \mathrm{C}$ in the angular frequency range varying from 0.1 to $100 \mathrm{rad}^{-1} \mathrm{~s}^{-1}$. The strain magnitude was fixed at $1 \%$ to stay in the linear domain. The thermal stability of samples was checked at $0.1 \mathrm{~Hz}$ for $15 \mathrm{~min}$ at the testing temperature.

\section{Results and discussion}

In order to observe the influence of nanodiamonds on the thermal and fire behavior of EVA composites, several compositions have been studied. In comparison with pure EVA, compositions containing ammonium polyphosphate (APP) flame retardant agent with different loadings (EVA/APP 20 and EVA/APP ${ }_{25}$ ), and compositions substituting a part of APP with nanodiamonds, either pure (EVA/APP $\left.{ }_{20} / \mathrm{ND}_{5}\right)$ or functionalized (EVA/APP ${ }_{20} / \mathrm{ND}-\mathrm{P}_{5}$ ) have been tested.

\subsection{Thermogravimetric analyses}

\subsubsection{Individual components}

The mass loss curves of the various individual components are shown in Fig. 1 and relevant parameters are presented in Table 2. It can be observed that the thermal degradation of EVA takes place in two 


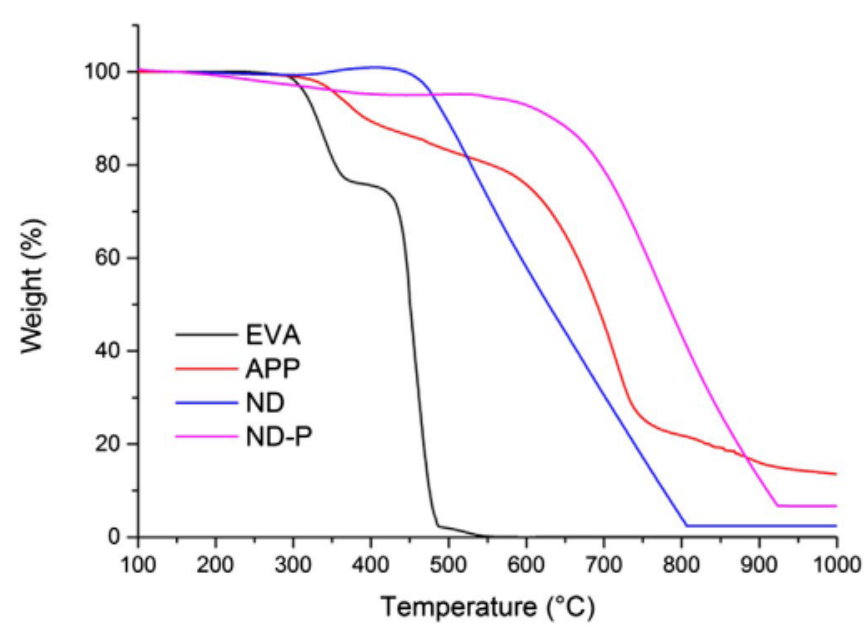

Fig. 1. TGA under air of individual components.

Table 2

Characteristic temperatures of degradation and residue amounts from TGA experiments in air.

\begin{tabular}{|c|c|c|c|c|c|}
\hline Samples & $\begin{array}{l}\mathrm{T} 10 \%^{\mathrm{a}} \\
\left({ }^{\circ} \mathrm{C} \pm 1\right)\end{array}$ & $\begin{array}{l}\text { Residue } \\
@ 500{ }^{\circ} \mathrm{C} \\
(\% \pm 0.1)\end{array}$ & $\begin{array}{l}\text { Residue } e^{\text {th b }} \\
@ 500^{\circ} \mathrm{C} \\
(\% \pm 0.1)\end{array}$ & $\begin{array}{l}\text { Residue } \\
@ 700{ }^{\circ} \mathrm{C} \\
(\% \pm 0.1)\end{array}$ & $\begin{array}{l}\text { Residue }^{\text {th b }} \\
@ 700^{\circ} \mathrm{C} \\
(\% \pm 0.1)\end{array}$ \\
\hline Pure EVA & 330 & 1.9 & 1.9 & 0.0 & 0.0 \\
\hline $\mathrm{EVA} / \mathrm{APP}_{20}$ & 335 & 20.6 & $18.1(+2.5)$ & 1.5 & $9.2(-7.7)$ \\
\hline $\mathrm{EVA} / \mathrm{APP}_{25}$ & 335 & 23.5 & $22.2(+1.3)$ & 1.6 & $11.5(-9.9)$ \\
\hline $\begin{array}{c}\text { EVA } / \text { APP }_{20} / \\
\mathrm{ND}_{5}\end{array}$ & 335 & 25.6 & $22.4(+3.2)$ & 6.1 & $10.7(-4.6)$ \\
\hline $\begin{array}{c}\text { EVA/APP } \\
\text { ND-P }_{5} /\end{array}$ & 340 & 24.0 & $22.7(+1.3)$ & 4.4 & $13.1(-8.7)$ \\
\hline
\end{tabular}

a Temperature corresponding to a $10 \%$ weight loss in the decomposition.

b The differences between experimental and calculated residues were indicated in brackets.

steps. As described in the literature [30] the first one between $300{ }^{\circ} \mathrm{C}$ and $400^{\circ} \mathrm{C}$ corresponds to a deacetylation process (elimination of acetic acid) with formation of conjugated polyenes and the second one is assigned to the degradation of the poly-unsaturated chains obtained after deacetylation. The presence of double bonds may induce cyclization/aromatization reactions leading to a char residue that degrades around $500{ }^{\circ} \mathrm{C}$. The decomposition of APP was studied in details by Camino et al. in the eighties [31]. It occurs in three different steps. The first two steps corresponding to a weight loss of circa $15 \%$ between 200 and $400{ }^{\circ} \mathrm{C}$ were attributed to the release of water and ammonia as gaseous products. The evolution of these gases induces the formation of acidic hydroxyl groups that enable a further crosslinking of the residue into ultraphosphate structures. The third step of degradation located around $650-700{ }^{\circ} \mathrm{C}$ corresponds to the fragmentation of phosphate chains. It leaves a complex phosphorus/nitrogen residue representing about $20 \%$ of the initial mass at $800{ }^{\circ} \mathrm{C}$ [32]. The decomposition of pure nanodiamond starts at $440{ }^{\circ} \mathrm{C}$ and finishes at $790{ }^{\circ} \mathrm{C}$ leaving almost no residue. As mentioned in a previous paper, phosphorylated nanodiamond (ND-P) exhibits a higher thermal stability in air than that of pure ND. Up to $600{ }^{\circ} \mathrm{C}$ the mass loss is lower than $10 \mathrm{wt} \%$. The main decomposition step occurs between 650 and $900{ }^{\circ} \mathrm{C}$ giving rise to a $6.5 \mathrm{wt} \%$ residue. This increase of oxidative stability was attributed to the condensation of the surface phosphate groups into polyphosphate species that create a protective layer at the ND surface [27].

\subsection{Composite materials}

Mass loss curves of composites materials are presented in Fig. 2. In order to emphasize interactions between components, theoretical mass loss curves (ML ${ }^{\text {th1 }}$ ) of composite samples have been calculated assum- ing a rule of mixture between the experimental mass losses (ML ${ }^{\text {exp }}$ ) of the different components:

$M L_{m i x}^{t h 1}(T)=X_{E V A} \times M L_{E V A}^{\exp }(T)+X_{A P P} \times M L_{A P P}^{\exp }(T)+X_{N D} \times M L_{N D}^{\exp }(T)$

where XEVA, XAPP and XND represent the weight fractions of EVA, APP and ND. A comparison between experimental and theoretical decomposition in air is proposed in Fig. 2. Theoretical residues (Residue $^{\text {th }}$ ) at 500 and $700{ }^{\circ} \mathrm{C}$ calculated according to the same rule of mixture are also noted in Table 2.

The results indicate that the presence of any additive does not affect the first step of EVA decomposition (i.e. deacetylation) since no difference is observed on the position of the first peak on the derivative mass loss curves (Fig. SI1). However from Fig. 2 it can be noted that the weight fraction remaining after this first degradation step is slightly higher than expected by calculation (of approx. $3 \mathrm{wt} \%$ ). It can be remarked that this intermediary residue increases with increasing APP content. From Fig. 1, it can be seen that the thermal decomposition of APP overlaps with the deacetylation process in EVA. Thus, APP may interact with the remaining polymer through crosslinking. This is similar to what was observed by Rimez et al. [33] in PVAc/APP systems. Nevertheless, it must be admitted that this effect remains small.

As regards the second decomposition step, the degradation onset is slightly retarded in the presence of additives (about $5^{\circ} \mathrm{C}$ ). This effect is slightly more significant in the case of ND-P with a shift of $10^{\circ} \mathrm{C}$. After the EVA main chain decomposition, an approximately $20 \mathrm{wt} \%$ residue is obtained. In all cases, the experimental residue amount is slightly higher than that calculated from a mixing law. However the discrepancy is almost the same as that observed after the first decomposition step. This indicates that APP has a poor ability to promote charring during the second decomposition step. The char residue is stable up to $600{ }^{\circ} \mathrm{C}$ where it starts decomposing. It should be noted that the char stability is increased with increasing APP content since char decomposition temperature is shifted by about $25^{\circ} \mathrm{C}$ when APP content varies from 20 to $25 \mathrm{wt} \%$. But surprisingly and contrary to what was expected from a simple rule of mixture, char yield and char stability are dramatically reduced in the range $650^{\circ} \mathrm{C}$ to $800{ }^{\circ} \mathrm{C}$. This was also observed by Siat et al. in PA6 [9]. As mentioned above, APP interferes with EVA during decomposition by crosslinking. Therefore the resulting residue differs from the ultraphosphate structure obtained with pure APP and consists rather in a phosphocarbonaceous structure [34] that decomposes from $600{ }^{\circ} \mathrm{C}$.

In the presence of ND (pure or phosphorylated), an additional residue is observed in the range $650^{\circ} \mathrm{C}$ to $800{ }^{\circ} \mathrm{C}$. Disturbingly, the residue of the composition containing pure $\mathrm{ND}$ is higher than that containing ND-P whereas taken separately ND-P has been shown to exhibit higher residue in this temperature range. In order to assess the interaction between ND (pure or phosphorylated) and APP a calculated curve can be plotted by using a rule of mixture between EVA/APP20 on one side and ND on the other side (Eq. (2)).

$M L_{m i x}^{t h 2}(T)=0.95 \times M L_{E V A / A P P 20}^{\exp }(T)+0.05 \times M L_{N D}^{\exp }(T)^{*}$

*It should be remarked that this rule of mixture gives a theoretical composition slightly different from the experimental one $(76 / 19 / 5$ instead of $75 / 20 / 5$ for EVA/APP/ND).

This second set of calculated curves indicates that at high temperature $\mathrm{EVA} / \mathrm{APP}_{20} / \mathrm{ND}-\mathrm{P}_{5}$ follows approximately a rule of mixture. Therefore no interaction between APP and ND-P is evidenced. On the contrary, the residual mass of EVA/APP ${ }_{20} / \mathrm{ND}$ was shown to be higher than calculated. This fact indicates an interaction between APP and pure ND resulting in the formation of a char residue which is stable up to $750{ }^{\circ} \mathrm{C}$. (See Fig. 3) 

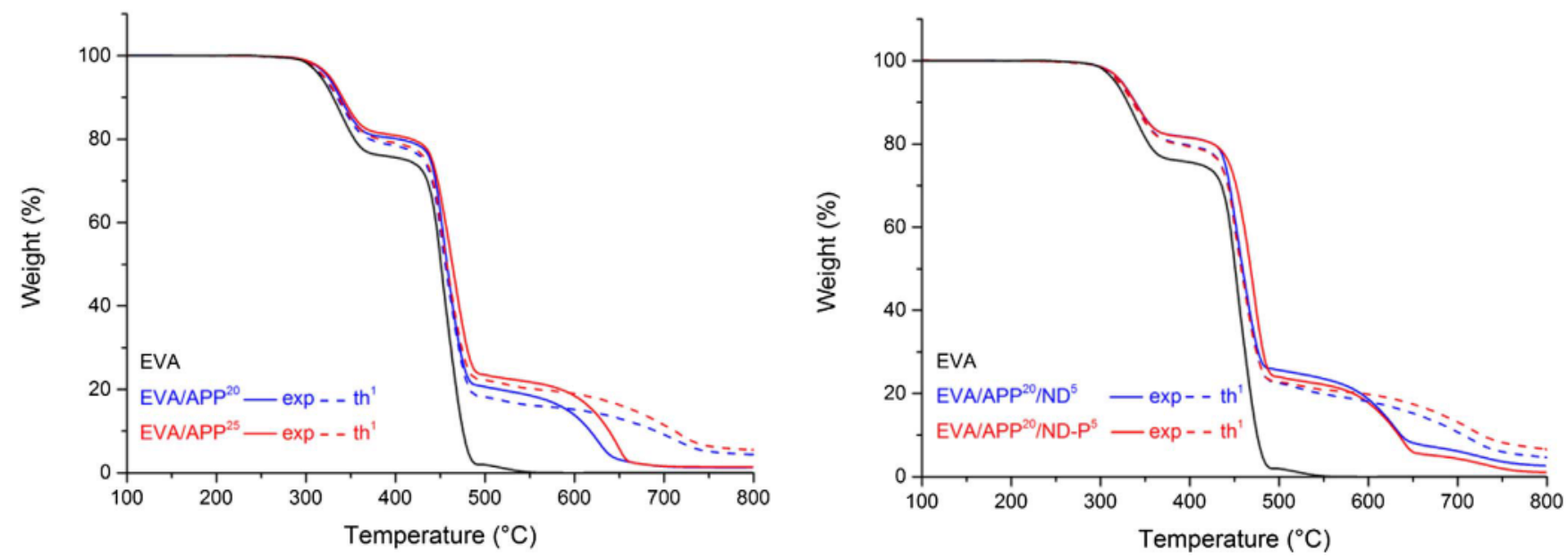

Fig. 2. Experimental and calculated ${ }^{(\text {thl })}$ TGA curves under air of composites.

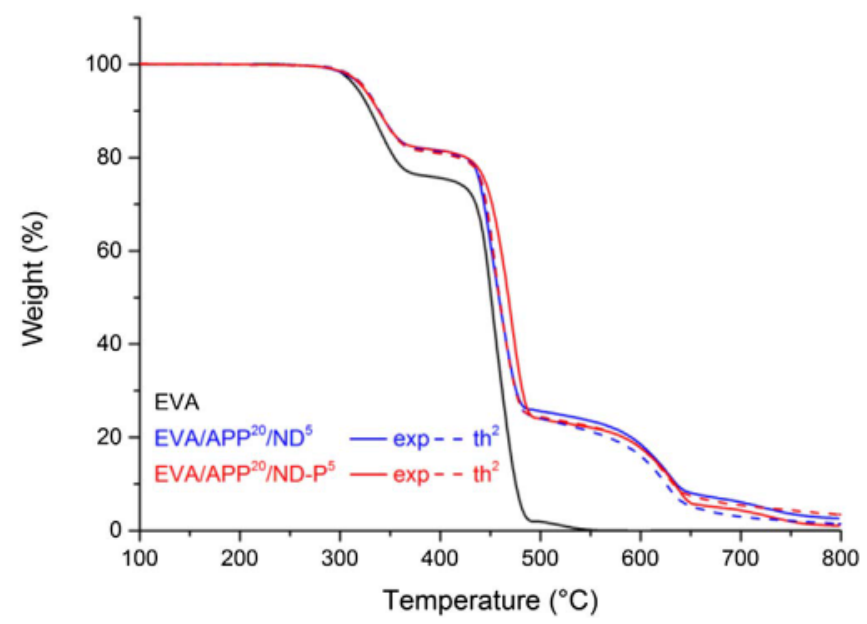

Fig. 3. Experimental and calculated ${ }^{\left(\text {th2 }^{2}\right)}$ TGA curves under air of composites.

\subsection{PCFC results}

Several information was obtained by PCFC analyses (Table 3): peak of heat release rate (pHRR) and temperature of pHRR (Tpeak) were recovered directly from the curves (Fig. 4). Sum of heat release capacity (sumHRC) and total heat release (THR) were mathematically extracted. Finally, effective heat combustion (EHC) was calculated from the THR value divided by the mass loss at the final temperature $\left(750{ }^{\circ} \mathrm{C}\right)$ obtained from TGA analysis.

Fig. 4 reveals that on the whole PCFC curves are relatively poorly modified in the presence of additives. The two steps of degradation occur at similar temperatures whatever the compositions. The main

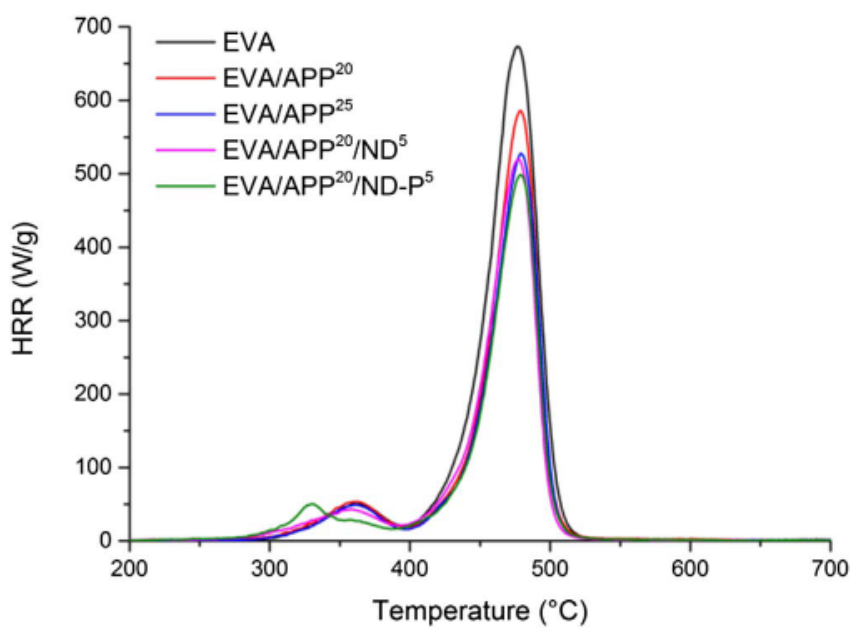

Fig. 4. PCFC curves.

pHRR is decreased by 20 to $25 \%$ that corresponds approximately, in these experiment conditions, to the additive content. The decrease of EHC indicates that the flame retardant system has an action in the vapor phase. The action may be related to the release of non or poorly combustible gases (i.e. water and ammonia) during APP decomposition. The presence of ND (pure or phosphorylated) does affect the main step of degradation of EVA. A slightly different behavior is observed for EVA/APP ${ }_{20} / \mathrm{ND}-\mathrm{P}_{5}$ in the $200{ }^{\circ} \mathrm{C}$ to $400{ }^{\circ} \mathrm{C}$ temperature range corresponding to the release of acetic acid. It was shown in Fig. 1 that ND-P exhibits a small weight loss (ca. $5 \%$ ) between 200 and $400{ }^{\circ} \mathrm{C}$. In a previous study this weight loss was attributed to the release of water resulting from the condensation of phosphate units at the ND surface

Table 3

Characteristic values from PCFC experiments.

\begin{tabular}{|c|c|c|c|c|c|}
\hline Sample & $\begin{array}{l}\mathrm{pHRR}^{\mathrm{a}} \\
\left(\mathrm{W} \cdot \mathrm{g}^{-1} \pm 5 \%\right)\end{array}$ & $\begin{array}{l}T_{\text {peak }}{ }^{b} \\
\left({ }^{\circ} \mathrm{C} \pm 1\right)\end{array}$ & $\begin{array}{l}\operatorname{sumHRC}^{c} \\
\left(\mathrm{~J} \cdot \mathrm{g}^{-1} \cdot \mathrm{K}^{-1} \pm 5 \%\right)\end{array}$ & $\begin{array}{l}\operatorname{THR}^{d} \\
\left(\mathrm{~kJ} \cdot \mathrm{g}^{-1} \pm 3 \%\right)\end{array}$ & $\begin{array}{l}\mathrm{EHC}^{\mathrm{e}} \\
\left(\mathrm{kJ} \cdot \mathrm{g}^{-1}\right)\end{array}$ \\
\hline Pure EVA & 679 & 479 & 728 & 33.3 & 33.3 \\
\hline $\mathrm{EVA} / \mathrm{APP}_{20}$ & 585 & 479 & 639 & 26.6 & 27.0 \\
\hline $\mathrm{EVA} / \mathrm{APP}_{25}$ & 530 & 479 & 583 & 24.9 & 25.3 \\
\hline $\mathrm{EVA} / \mathrm{APP}_{20} / \mathrm{ND}_{5}$ & 518 & 477 & 560 & 24.7 & 25.7 \\
\hline EVA $/$ APP $_{20} /$ ND-P $_{5}$ & 497 & 479 & 546 & 23.4 & 23.9 \\
\hline
\end{tabular}

a pHRR: peak of Heat Release Rate.

b $\mathrm{T}_{\text {peak: }}$ : temperature corresponding to the pHRR.

c sumHRC: Heat Release Capacity, obtained as sum of the two pHRR values divided by the heating rate.

d THR: Total Heat Release, calculated from the total.

e EHC: Effective Heat of Combustion, corresponding to the THR value divided by the mass loss at the finale temperature (e.g. $750{ }^{\circ} \mathrm{C}$ ). 


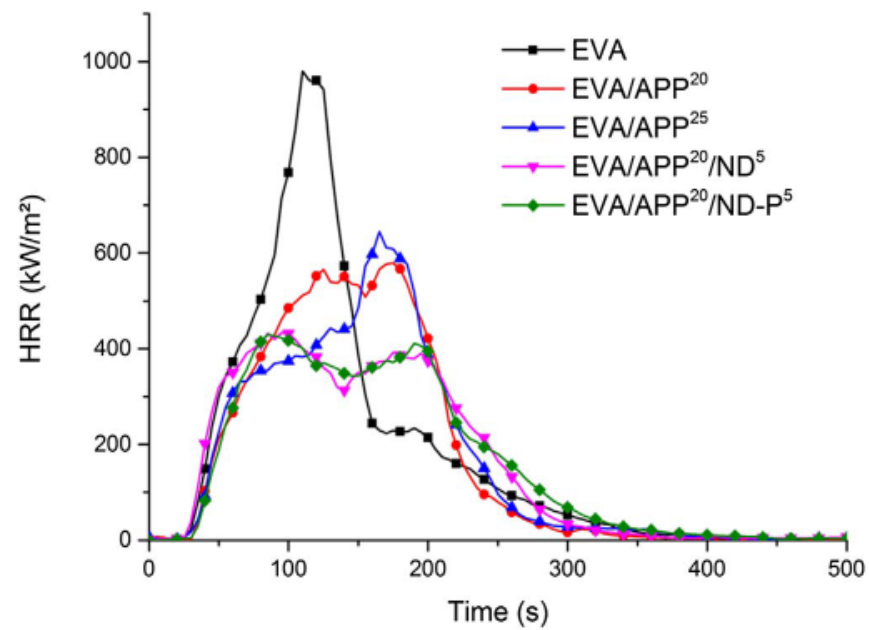

Fig. 5. Heat Release Rate (HRR) curves from cone calorimeter tests under $50 \mathrm{~kW} \cdot \mathrm{m}^{-2}$ irradiance.

[27]. The release of water is likely to induce the early hydrolysis of EVA into EVOH with release of acetic acid. This phenomenon occurs $30^{\circ} \mathrm{C}$ lower than thermal deacetylation, as seen on Fig.5. However, it seems not to impinge the rest of the thermal decomposition. It shall be noted that no heat release was observed in the range $550-700^{\circ} \mathrm{C}$. This confirms that the amount of char must be very small in these compositions. Furthermore, the weight loss observed in TGA curves around $600{ }^{\circ} \mathrm{C}$ is mainly related to the decomposition of APP residue with evolution of phosphate fragments that do not behave as fuel.

\subsection{Cone calorimetry results}

Complete results of cone calorimetry for the different composites are shown in Table 4. Heat release rate (HRR) and mass loss rate (MLR) curves are presented in Figs. 5 and 6. To obtain the effective heat of combustion (EHC), THR is divided by the final mass loss. Finally, pictures of the aspect of the residue are shown in Fig. 9.

Fig. 5 shows that whatever the composition TTI remains almost constant with value between 26 and $28 \mathrm{~s}$. This result may be counterintuitive since it is known from the literature that NDs tend to increase the thermal conductivity of polymers [35]. Therefore heat should have been transferred more rapidly to the back of the sample and an increase of TTI could have been expected. However it seems that the concomitant presence of APP and ND do not promote such a phenomenon. The results indicate that flame retardant additives act mainly after ignition. In the case of EVA/APP compositions the PHRR is decreased by 30 to $40 \%$. However the shape of the curve remains unchanged with the peak occurring near the exhaustion of fuel. It should be noted that the residue yield is $12.8 \%$ and $18.3 \%$ respectively for 20 and $25 \%$ APP loading. These values are higher than for TGA residues determined at $700{ }^{\circ} \mathrm{C}$. They correspond approximately to TGA residue measured at

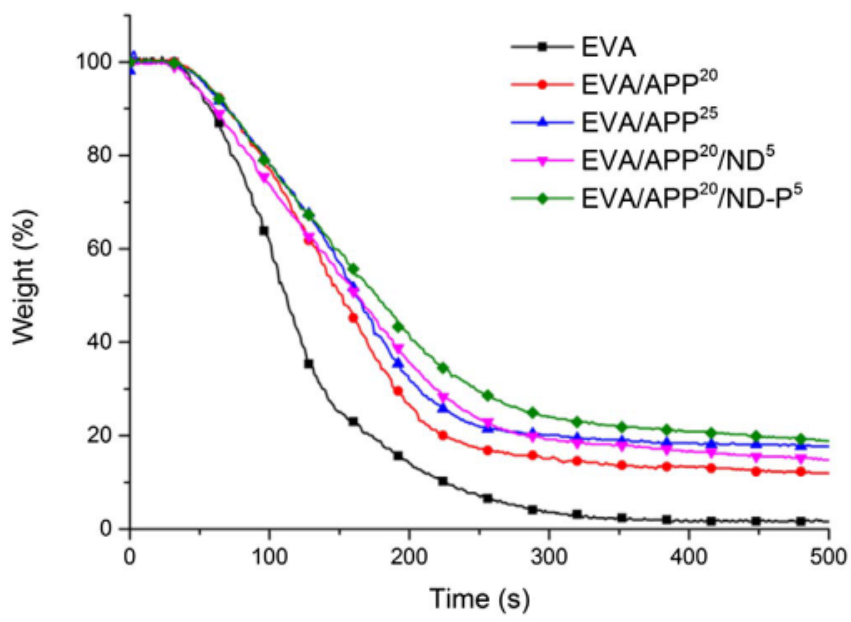

Fig. 6. Mass Loss Rate (MLR) curves from cone calorimeter tests under $50 \mathrm{kWm}^{-2}$ irradiance.

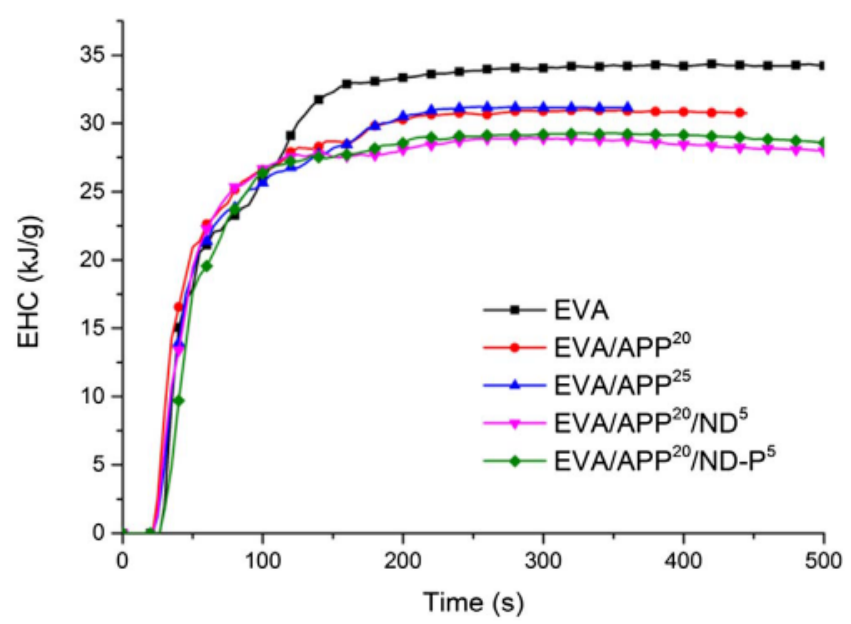

Fig. 7. Effective Heat of Combustion (EHC) evolution during cone calorimeter tests under $50 \mathrm{~kW} \cdot \mathrm{m}^{-2}$ irradiance.

$600{ }^{\circ} \mathrm{C}$, meaning that the temperature reached by the condensed phase in cone calorimeter was not higher than this value. No further charring was evidenced. A small decrease of EHC of approximately $12 \%$ was observed. As previously mentioned this decrease can be assigned to the release of non-combustible gases during APP decomposition.

The results obtained with EVA/APP/ND compositions are much more interesting. In the presence of ND (pure or modified) pHRR is decreased by $65 \%$ with values around $450 \mathrm{~kW} \cdot \mathrm{m}^{-2}$. Moreover, the shape of HRR curve is significantly changed with the peak occurring shortly after ignition. After the peak, HRR slowly decreases what corresponds to a controlled release of fuel. This allegation is supported

Table 4

Cone calorimeter data.

\begin{tabular}{|c|c|c|c|c|c|}
\hline Sample & $\begin{array}{l}\mathrm{TTI}^{\mathrm{a}} \\
(s \pm 1)\end{array}$ & $\begin{array}{l}\mathrm{pHRR}^{\mathrm{b}} \\
\left(\mathrm{kW} \cdot \mathrm{m}^{-2} \pm 5 \%\right)\end{array}$ & $\begin{array}{l}\mathrm{THR}^{\mathrm{c}} \\
(\mathrm{kJ} \cdot \mathrm{g} \pm 1 \%)\end{array}$ & $\begin{array}{l}\mathrm{EHC}^{\mathrm{d}} \\
\left(\mathrm{MJ} \cdot \mathrm{kg}^{-1} \pm 5 \%\right)\end{array}$ & $\begin{array}{l}\text { Residue } \\
(\% \pm 0.1)\end{array}$ \\
\hline Pure EVA & 28 & 980 & 33.8 & 34.2 & 1.2 \\
\hline $\mathrm{EVA} / \mathrm{APP}_{20}$ & 27 & 604 & 26.1 & 30.0 & 12.8 \\
\hline $\mathrm{EVA} / \mathrm{APP}_{25}$ & 26 & 684 & 25.6 & 31.4 & 18.3 \\
\hline $\mathrm{EVA} / \mathrm{APP}_{20} / \mathrm{ND}_{5}$ & 26 & 435 & 24.5 & 28.4 & 13.6 \\
\hline $\mathrm{EVA} / \mathrm{APP}_{20} / \mathrm{ND} \mathrm{P}_{5}$ & 28 & 455 & 24.3 & 28.7 & 15.3 \\
\hline
\end{tabular}

a TTI: Time-to-Ignition.

b pHRR: peak of Heat Release Rate.

c THR: Total Heat Release.

${ }^{d}$ EHC: Effective Heat of Combustion, corresponding to the THR divided by the final mass loss. 


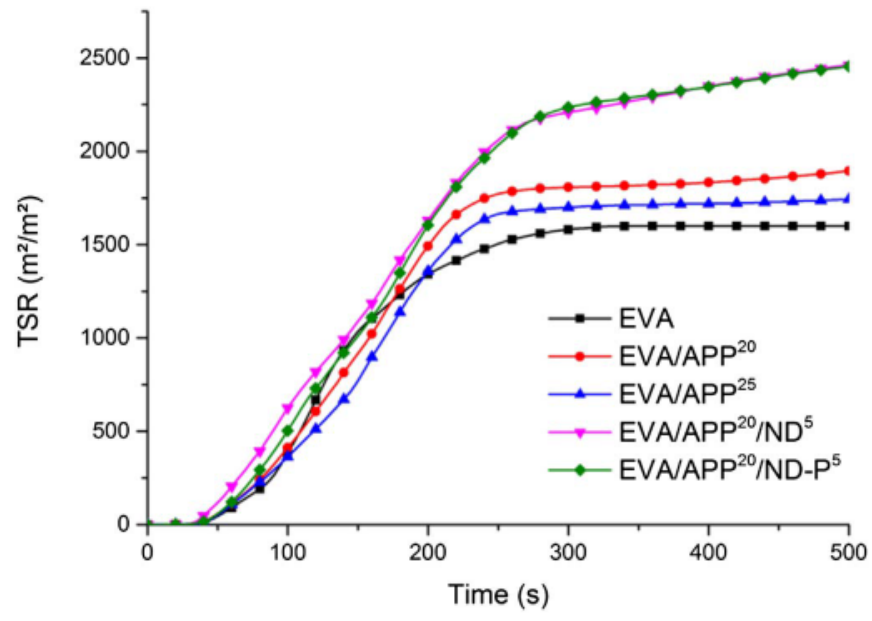

Fig. 8. Total Smoke Release (TSR) Cone curves from cone calorimeter tests under $50 \mathrm{~kW} \mathrm{~m}^{-2}$ irradiance.

by the mass loss curve as shown in Fig. 6 . In the range $100 \mathrm{~s}$ to $300 \mathrm{~s}$ the mass loss rate is significantly lower for ND containing compositions. This type of curves corresponds to a thick charring behavior according to the classification of Schartel and Hull [36]. This behavior is encountered when a protective layer acting as barrier for heat and mass transfer is built at the surface of the sample. From Table 4 it can be seen that the global EHC is lowered in ND containing compositions.

EHC can be also calculated at any time $t$ of the experiment by dividing the cumulative heat release by the mass loss at the corresponding time t. Fig. 7 presents the evolution of EHC as a function of time for the various compositions. It is noteworthy that in the case of pure EVA, EHC increases progressively from 21 to $35 \mathrm{~kJ} \cdot \mathrm{g}^{-1}$. The initial value corresponds approximately to that of acetic acid which is the early decomposition product of the polymer matrix. The further EHC increase can be related to the contribution of ethylenic fragments with a higher intrinsic combustion energy (circa $42 \mathrm{~kJ} \cdot \mathrm{g}^{-1}$ ). In the case of EVA/APP compositions, the evolution of EHC is relatively similar with a lower final value $\left(31 \mathrm{~kJ} \cdot \mathrm{g}^{-1}\right)$ due to the release of water and ammonia that do not contribute to the combustion. Despite the fact that ND containing compositions should release decomposition products similar to those of EVA/APP compositions, their EHC reach rapidly a lower constant value of approximately $27 \mathrm{~kJ}^{-1}$. This means that in this case combustion shall be incomplete. This hypothesis is confirmed by the higher total smoke release (TSR) observed from the first peak of HRR (Fig. 8). Furthermore, it should be remarked that the residue yields in the presence of ND are in the same range than with APP solely. Thus it may be suspected that the difference between EVA/APP and EVA/APP/ND behaviors lies in their residue structuration that plays an important role on its flame retardant efficiency.

\subsection{Electronic microscopy}

This hypothesis of different residue structuration is confirmed by pictures taken at macroscale and presented in Fig. 9. EVA/APP residues are thin and poorly cohesive while EVA/APP/ND residues are thicker and seem more cohesive. Moreover, a slight swelling of residues was
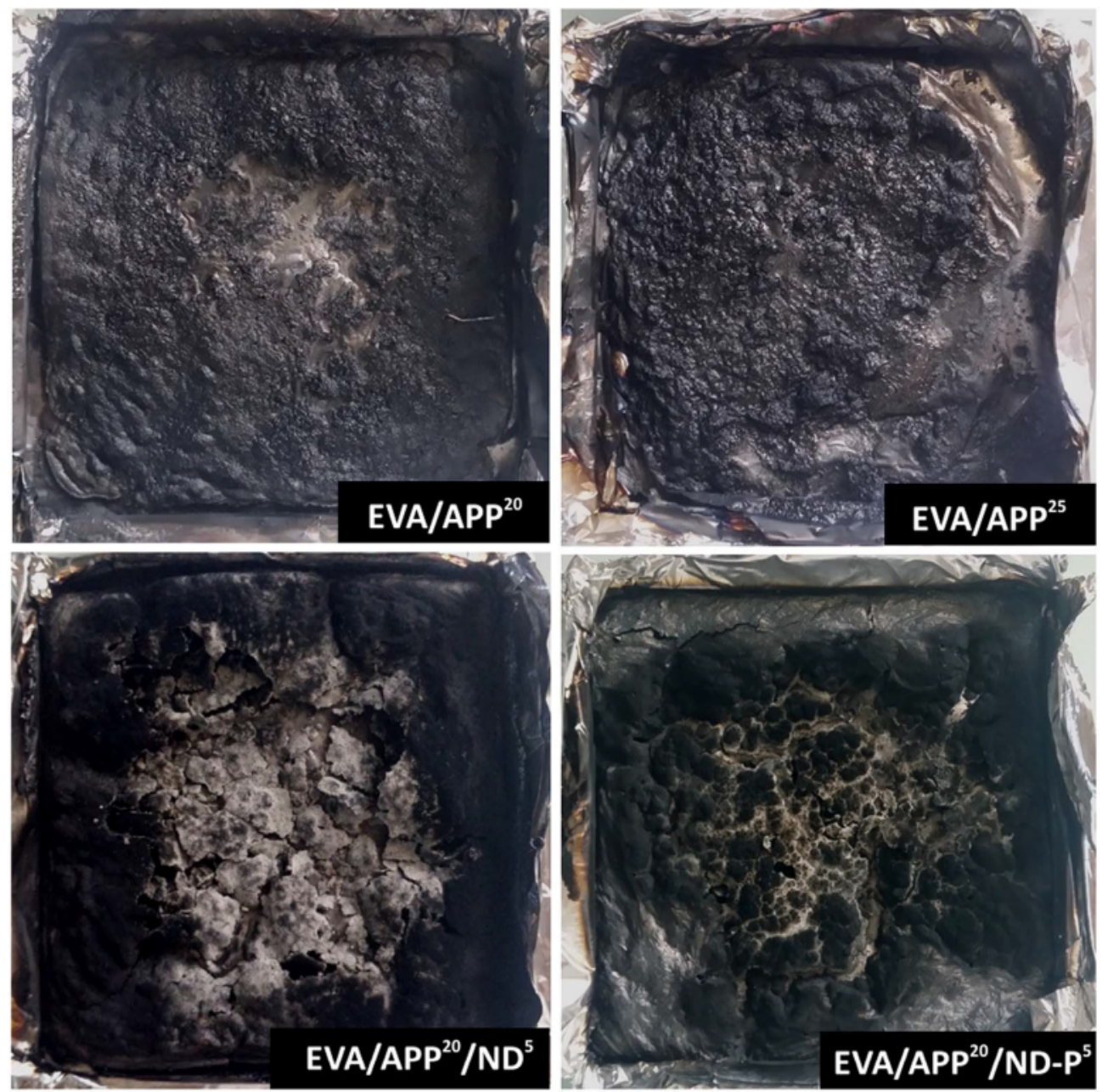

Fig. 9. Cone calorimeter tests: residue aspect. 


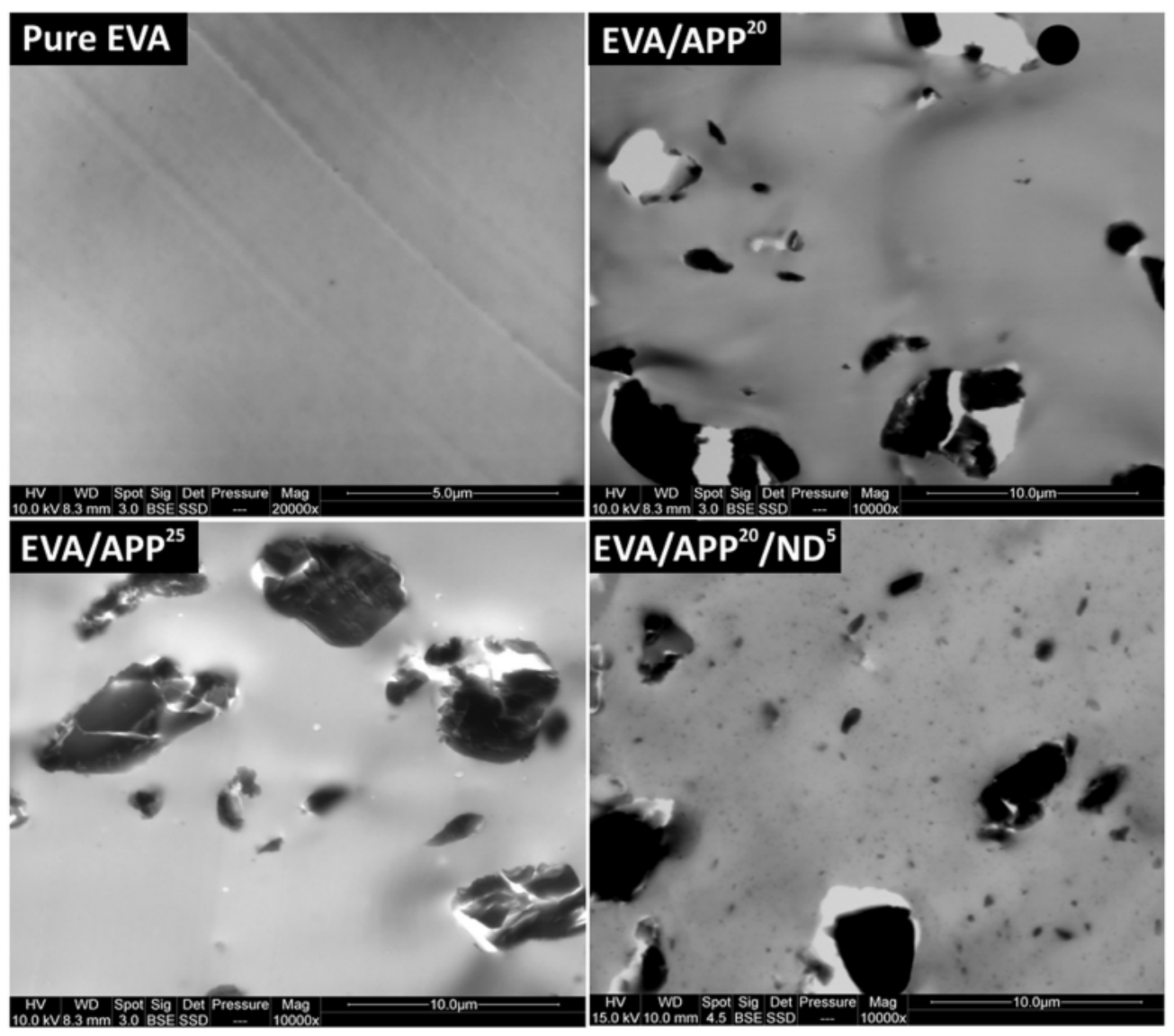

Fig. 10. STEM images of composites.

observed during the test giving rise to surface relief with irregularities. This swelling cannot obviously be compared to that of intumescent systems. However expansion is generally considered as beneficial for the thermal shield properties of the residue [37].

In order to better understand the fire behavior observed in cone calorimeter test, the microstructure of composites before burning was investigated by STEM. Fig. 10 shows the morphology of the various compositions at microscopic scale. From the observation of EVA/APP compositions, it can be noticed that APP consists of micron-sized particles with diameter ranging from $5 \mu \mathrm{m}$ to $10 \mu \mathrm{m}$. In EVA/APP/ND compositions micron-sized APP particles can also be observed. Additionally, submicron particles are evidenced. Intuitively these particles are supposed to be aggregates of ND. To confirm this hypothesis, EDX mapping was carried out on ND containing samples. Fig. 11 shows carbon, oxygen and phosphorus cartography. Surprisingly, it was highlighted that some of the submicron particles contain only phosphorus and oxygen. This result was attributed to the fragmentation of APP particles in the presence of ND. Due to their hardness and the frictional forces involved during processing, ND particles are likely to break APP particles. As a consequence APP is better finely dispersed in the EVA matrix when ND is present. This could be one of the reasons for the more homogeneous charred layer observed in EVA/APP/ND compositions.

\subsection{Rheology}

It is recognized that the rheological properties may play a dominant role in the fire behavior of polymeric materials because different phenomena such as bubbling or barrier formation are governed by viscosity [38]. Fig. 12 shows the complex viscosity of pure EVA and some composite formulations. It can be noticed that EVA exhibits a nonNewtonian behavior with a decrease of viscosity with increasing frequency typical of shear-thinning. A similar behavior was observed for EVA/ND and EVA/APP systems with viscosity slightly higher than the pure polymer. Singularly EVA/APP/ND composition exhibits a very different rheological behavior with an increase of viscosity as angular frequency increases. This behavior can be considered as shear-thickening. It is thought that the higher viscosity of the ND containing composition may act favorably on the cohesion and swelling of the protective layer during its formation as evidenced in Fig. 9.

\section{Conclusion}

The interest of combinations of pristine or modified nanodiamond (ND) and Ammonium Polyphosphate (APP) to improve the reaction to fire of ethylene vinyl acetate (EVA) has been shown. Thermal analysis indicates an interaction between the degradation of APP and ND, which leads to the enhancement of the char residue stability, but only up to $750{ }^{\circ} \mathrm{C}$. A strong reduction in peak of heat release at cone calorimeter was observed for APP/ND combinations in comparison with APP alone in EVA at the same global loading. A synergistic effect on total heat released (THR) was also noticed. The formation of a thick charring residue was observed by SEM and it can be supposed that the incorporation of ND particles tends to improve the cohesion of the residue. This improvement could result from both the grinding effect of APP by the ND particles and the increase of viscosity in the joint presence of APP and ND. Moreover, despite a better thermal stability of modified ND, no significant difference appears between pristine and phosphorylated ND, regarding the thermal stability and fire behavior of nanocomposites. Among the perspectives of this work, the study of FR systems combining a charring polymer with APP/ND blends in EVA seems of prime interest, to investigate if ND can play a potential role of synergistic agent in intumescent compositions.

Supplementary data to this article can be found online at http://dx. 

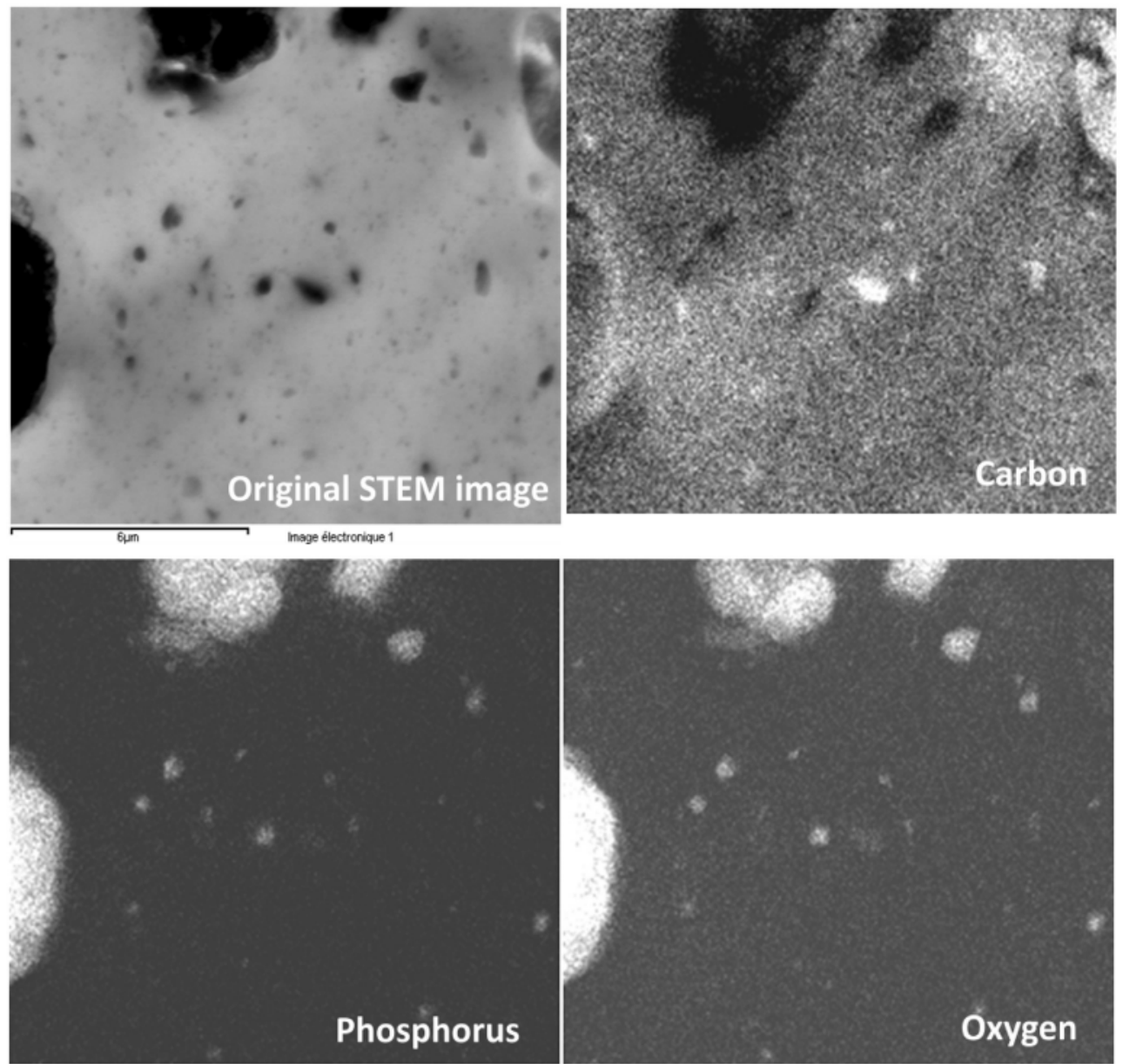

Fig. 11. Element Maps for C, $P$ and $O$ in EVA/APP20/ND5 sample using EDX.

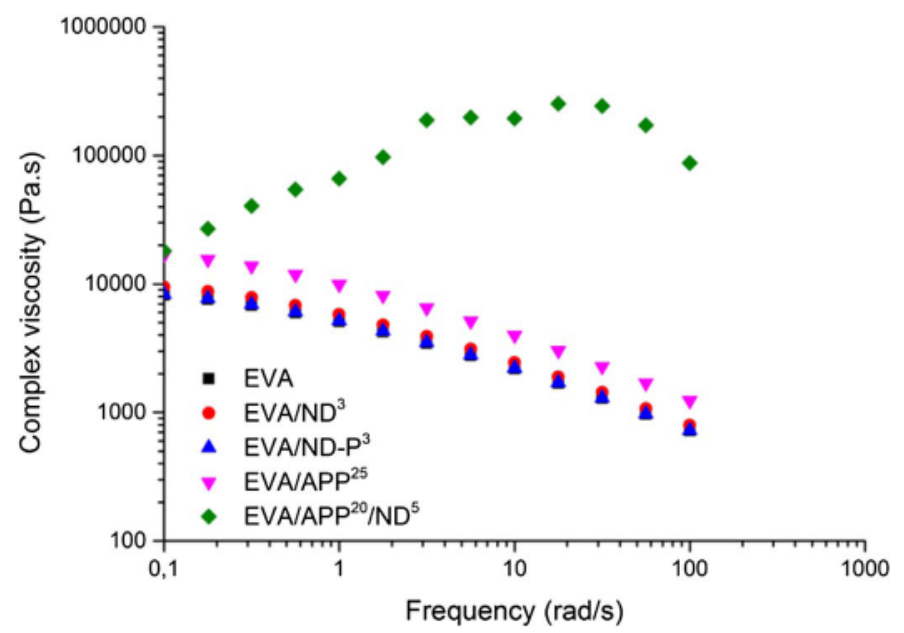

Fig. 12. Complex viscosity as a function of angular frequency for various compositions $\left(T=150^{\circ} \mathrm{C}\right.$, strain $\left.=1 \%\right)$.

doi.org/10.1016/j.diamond.2017.05.002.

\section{References}

[1] K. McGarry, J. Zilberman, T.R. Hull, W.D. Woolley, Decomposition and combustion of EVA and LDPE alone and when fire retarded with ATH, Polym. Int. 49 (2000) 1193-1198.

[2] R.N. Rothon, P.R. Hornsby, Flame retardant effects of magnesium hydroxide, Polym. Degrad. Stab. 54 (1996) 383-385.

[3] A. Durin-France, L. Ferry, J.-M. Lopez Cuesta, A. Crespy, Magnesium hydroxide/ zinc borate/talc compositions as flame-retardants in EVA copolymer, Polym. Int. 49 (2000) 1101-1105.
[4] L. Clerc, L. Ferry, E. Leroy, J.M. Lopez-Cuesta, Influence of talc physical properties on the fire retarding behaviour of (ethylene-vinyl acetate copolymer/magnesium hydroxide/talc) composites, Polym. Degrad. Stab. 88 (2005) 504-511.

[5] L. Haurie, A.I. Fernández, J.I. Velasco, J.M. Chimenos, J.-M. Lopez Cuesta,

F. Espiell, Thermal stability and flame retardancy of LDPE/EVA blends filled with synthetic hydromagnesite/aluminium hydroxide/montmorillonite and magnesium hydroxide/aluminium hydroxide/montmorillonite mixtures, Polym. Degrad. Stab. 92 (2007) 1082-1087.

[6] F. Laoutid, P. Gaudon, J.-M. Taulemesse, J.M. Lopez Cuesta, J.I. Velasco, A. Piechaczyk, Study of hydromagnesite and magnesium hydroxide based fire retardant systems for ethylene-vinyl acetate containing organo-modified montmorillonite, Polym. Degrad. Stab. 91 (2006) 3074-3082.

[7] F. Laoutid, L. Ferry, E. Leroy, J.M. Lopez Cuesta, Intumescent mineral fire retardant 
systems in ethylene-vinyl acetate copolymer: effect of silica particles on char cohesion, Polym. Degrad. Stab. 91 (2006) 2140-2145.

[8] M. Le Bras, S. Bourbigot, B. Revel, Comprehensive study of the degradation of an intumescent EVA-based material during combustion, J. Mater. Sci. 34 (1999) 5777-5782.

[9] C. Siat, S. Bourbigot, M. Le Bras, Thermal behaviour of polyamide-6-based intumescent formulations—a kinetic study, Polym. Degrad. Stab. 58 (1997) 303-313.

[10] A. Riva, G. Camino, L. Fomperie, P. Amigouët, Fire retardant mechanism in intumescent ethylene vinyl acetate compositions, Polym. Degrad. Stab. 82 (2003) 341-346.

[11] J. Alongi, M. Pošsković, A. Frache, F. Trotta, Novel flame retardants containing cyclodextrin nanosponges and phosphorus compounds to enhance EVA combustion properties, Polym. Degrad. Stab. 95 (2010) 2093-2100.

[12] T. Zhang, H. Yan, L. Shen, Z. Fang, X. Zhang, J. Wang, Chitosan/Phytic Acid Polyelectrolyte Complex: A Green and Renewable Intumescent Flame Retardant System for Ethylene - Vinyl Acetate Copolymer, (2014).

[13] F. Dabrowski, M. Le Bras, L. Cartier, S. Bourbigot, The use of clay in an EVA-based intumescent formulation. Comparison with the intumescent formulation using polyamide-6 clay Nanocomposite as carbonisation agent, J. Fire Sci. 19 (2001) 219-241.

[14] N.A. Isitman, C. Kaynak, Nanoclay and carbon nanotubes as potential synergists of an organophosphorus flame-retardant in poly(methyl methacrylate), Polym. Degrad. Stab. 95 (2010) 1523-1532.

[15] X. Wu, L. Wang, C. Wu, G. Wang, P. Jiang, Flammability of EVA/IFR (APP/PER/ZB system) and EVA/IFR/synergist $\left(\mathrm{CaCO}_{3}, \mathrm{NG}\right.$, and EG) composites, J. Appl. Polym. Sci. 126 (2012) 1917-1928.

[16] J.N. Gavgani, H. Adelnia, M.M. Gudarzi, Intumescent flame retardant polyurethane/reduced graphene oxide composites with improved mechanical, thermal, and barrier properties, J. Mater. Sci. 49 (2013) 243-254.

[17] X. Wu, L. Wang, C. Wu, J. Yu, L. Xie, G. Wang, P. Jiang, Influence of char residues on flammability of EVA/EG, EVA/NG and EVA/GO composites, Polym. Degrad. Stab. 97 (2012) 54-63.

[18] G. Huang, J. Yang, J. Gao, X. Wang, Thin films of intumescent flame retardantpolyacrylamide and exfoliated graphene oxide fabricated via layer-by-layer assembly for improving flame retardant properties of cotton fabric, Ind. Eng. Chem. Res. 51 (2012) 12355-12366.

[19] T. Kashiwagi, E. Grulke, J. Hilding, K. Groth, R. Harris, K. Butler, J. Shields, S. Kharchenko, J. Douglas, Thermal and flammability properties of polypropylene/ carbon nanotube nanocomposites, Polymer 45 (2004) 4227-4239 (Guildf).

[20] S. Peeterbroeck, F. Laoutid, B. Swoboda, J.-M. Lopez-Cuesta, N. Moreau, J.B. Nagy, M. Alexandre, P. Dubois, How carbon nanotube crushing can improve flame retardant behaviour in polymer nanocomposites? Macromol. Rapid Commun. 28 (2007) 260-264.

[21] G. Huang, J. Gao, X. Wang, H. Liang, C. Ge, How can graphene reduce the flammability of polymer nanocomposites? Mater. Lett. 66 (2012) 187-189.

[22] G. Huang, S. Wang, P. Song, C. Wu, S. Chen, X. Wang, Combination effect of carbon nanotubes with graphene on intumescent flame-retardant polypropylene nanocomposites, Compos. A: Appl. Sci. Manuf. 59 (2014) 18-25.
[23] V.N. Mochalin, O. Shenderova, D. Ho, Y. Gogotsi, The properties and applications of nanodiamonds, Nat. Nanotechnol. 7 (2011) 11-23.

[24] O. Faklaris, V. Joshi, T. Irinopoulou, P. Tauc, M. Sennour, H. Girard, C. Gesset, J.C. Arnault, A. Thorel, J.-P. Boudou, et al., Photoluminescent diamond nanoparticles for cell labeling: study of the uptake mechanism in mammalian cells, ACS Nano 3 (2009) 3955-3962.

[25] A. Krueger, Diamond nanoparticles: jewels for chemistry and physics, Adv. Mater. 20 (2008) 2445-2449.

[26] H.A. Girard, J.C. Arnault, S. Perruchas, S. Saada, T. Gacoin, J.P. Boilot, P. Bergonzo, Hydrogenation of nanodiamonds using MPCVD: a new route toward organic functionalization, Diam. Relat. Mater. 19 (2010) 1117-1123.

[27] C. Presti, J.G. Alauzun, D. Laurencin, P.H. Mutin, Improvement of the oxidative stability of nanodiamonds by surface phosphorylation, Chem. Mater. 25 (2013) 2051-2055.

[28] C. Presti, J.G. Alauzun, D. Laurencin, P.H. Mutin, Surface functionalization of detonation nanodiamonds by phosphonic dichloride derivatives, Langmuir 30 (2014) 9239-9245.

[29] C. Presti, A.S.L. Thankamony, J.G. Alauzun, P.H. Mutin, D. Carnevale, C. Lion, H. Vezin, D. Laurencin, O. Lafon, NMR and EPR characterization of functionalized nanodiamonds, J. Phys. Chem. C 119 (2015) 12408-12422.

[30] N.S. Allen, M. Edge, M. Rodriguez, C.M. Liauw, E. Fontan, Aspects of the thermal oxidation of ethylene vinyl acetate copolymer, Polym. Degrad. Stab. 68 (2000) 363-371.

[31] G. Camino, L. Costa, L. Trossarelli, Study of the mechanism of intumescence in fire retardant polymers: part V-mechanism of formation of gaseous products in the thermal degradation of ammonium polyphosphate, Polym. Degrad. Stab. 12 (1985) 203-211.

[32] P.J. Davies, A.R. Horrocks, A. Alderson, The sensitisation of thermal decomposition of ammonium polyphosphate by selected metal ions and their potential for improved cotton fabric flame Retardancy, Polym. Degrad. Stab. 88 (2005) 114-122.

[33] B. Rimez, H. Rahier, M. Biesemans, S. Bourbigot, B. Van Mele, Flame retardancy and degradation mechanism of poly(vinyl acetate) in combination with intumescent flame retardants: I. Ammonium poly(phosphate), Polym. Degrad. Stab. 121 (2015) 321-330.

[34] S. Bourbigot, M. Le Bras, R. Delobel, P. Bréant, J. Trémillon, Michel, Carbonization mechanisms resulting from intumescence-part II. Association with an ethylene terpolymer and the ammonium polyphosphate-pentaerythritol fire retardant system, Carbon 33 (1995) 283-294.

[35] V.N. Mochalin, Y. Gogotsi, Nanodiamond-polymer composites, Diam. Relat. Mater. 58 (2015) 161-171.

[36] B. Schartel, T.R. Hull, Development of fire-retarded materials-interpretation of cone calorimeter data, Fire Mater. 31 (2007) 327-354.

[37] X. Ren, R. Zong, Y. Hu, S. Lo, A.A. Stec, T.R. Hull, Numerical simulation of decomposition of polymer nano-composites: investigation of the influence of the char structure, Energy Procedia 66 (2015) 165-168.

[38] J. Courtat, F. Melis, J.-M. Taulemesse, V. Bounor-Legare, R. Sonnier, L. Ferry, P. Cassagnau, Effect of phosphorous-modified silica on the flame retardancy of polypropylene based nanocomposites, Polym. Degrad. Stab. 119 (2015) 260-274. 